\title{
Long-term recurrence and brain metastasis of nasopharyngeal carcinoma mimicking cystic radiation encephalopathy relapse: a case report
}

Xuhui Chen ${ }^{1}$, Lijie Ren ${ }^{2,3}$, Guozhen Qiu $^{4}$ and Liming Cao $^{2,4^{*}}$ (D)

\begin{abstract}
Background: During medical imaging, cystic radiation encephalopathy and brain metastasis are difficult to differentiate, and hence they are easily misdiagnosed. To our knowledge, a nasopharyngeal carcinoma recurrence after more than seven years with cerebral metastasis that mimicked cystic radiation encephalopathy has not been reported.
\end{abstract}

Case presentation: A 52-year-old man was admitted to the hospital owing to weakness of the right limb for one month, which increased in intensity for three days. He had been diagnosed with nasopharyngeal carcinoma in 2011, which was treated by radiotherapy. The patient successively developed cystic radiation encephalopathy and brain metastasis from the nasopharyngeal carcinoma, which mimicked cystic radiation encephalopathy relapse. Left frontotemporal craniotomy, surgical resection of brain metastasis, and repair of the skull base and dura were performed. Postoperative computed tomography showed that midline deviation recovered, and brain edema was reduced.

Conclusions: This report is significant because brain metastasis from nasopharyngeal carcinoma can masquerade as a benign entity and cause fatal consequences. In patients presenting with cystic radiation encephalopathy, brain metastasis should be considered as a differential diagnosis.

Keywords: Nasopharyngeal carcinoma, Brain metastasis, Radiation encephalopathy, Magnetic resonance imaging, Case report

\footnotetext{
* Correspondence: caolm-2007@163.com

${ }^{2}$ Department of Neurology, Shenzhen University First Affiliated Hospital, 3002

Sungang West Road, Futian District 518000 Shenzhen, China

${ }^{4}$ Department of Neurology, The 3rd Affiliated Hospital of Shenzhen

University, 518000 Shenzhen, China

Full list of author information is available at the end of the article
}

C C The Author(s). 2021 Open Access This article is licensed under a Creative Commons Attribution 4.0 International License, which permits use, sharing, adaptation, distribution and reproduction in any medium or format, as long as you give appropriate credit to the original author(s) and the source, provide a link to the Creative Commons licence, and indicate if changes were made. The images or other third party material in this article are included in the article's Creative Commons licence, unless indicated otherwise in a credit line to the material. If material is not included in the article's Creative Commons licence and your intended use is not permitted by statutory regulation or exceeds the permitted use, you will need to obtain permission directly from the copyright holder. To view a copy of this licence, visit http://creativecommons.org/licenses/by/4.0/. The Creative Commons Public Domain Dedication waiver (http://creativecommons.org/publicdomain/zero/1.0/) applies to the data made available in this article, unless otherwise stated in a credit line to the data. 


\section{Background}

Nasopharyngeal carcinoma (NPC) is a particularly prevalent carcinoma in Southern China for which radiotherapy is the primary treatment. A side effect is radiation encephalopathy (RE), a common and serious complication that is irreversible and life-threatening. The 3- and 5-year incidences of RE following radiotherapy are reported to be 10.8 and $34.9 \%$, respectively [1]. Another reason for treatment failure is recurrence or metastasis of NPC. Approximately 15$30 \%$ of patients with NPC develop metastasis after completion of radiotherapy and chemotherapy [2]. The common sites for distant metastasis are the lungs, liver, bones, and retroperitoneal lymph nodes [3]. Brain metastasis of NPC is even rarer, ranging from 0.71 to $0.85 \%$ of NPC cases $[4,5]$, and the clinical characteristics remain poorly understood. Differentiation between cystic RE and brain metastasis is difficult. A study [6] reported $14 \%$ of the patients developed local recurrence, while $21 \%$ had distant metastasis at the time of local relapse. Among those with NPC recurrence, $41 \%$ had local recurrence detected within the first two years, $44 \%$ in the 2 nd to 5 th year, and $15 \%$ were detected $>5$ years later. Most distant metastases in NPC occur within three years after radiotherapy completion [7].To our knowledge, an NPC recurrence after more than seven years with cerebral metastasis that mimicked cystic RE has not been reported. We present a patient with long-term recurrence and brain metastasis of NPC, which mimicked cystic RE, and a review of the literature. We provided useful information about the differential diagnosis between these two entities.

\section{Case presentation}

In September 2017, a 52-year-old man was admitted to the hospital owing to weakness of the right limb for one month with increased intensity for three days. In 2011, he was treated for nasopharyngeal carcinoma with radiotherapy and chemotherapy. He had speech impairment, difficulty in mouth opening, dysphagia, and repeated pulmonary infections from the sequelae of NPC. Head computed tomography (CT) three years after onset indicated RE (film not available).

He had a history of anxiety and no history of major trauma, toxic exposure, or hereditary disease. Physical examination showed blood pressure of 90/ $61 \mathrm{mmHg}$, clear consciousness, vague speech, decreased memory, shallow nasolabial sulcus on the right, disappearance of pharyngeal reflex, decrease of muscle strength on the right upper and lower limbs $(4 / 5)$, increased muscle tension in the right upper limb, and positive pyramidal sign on the right side.
Emergency head CT showed solid-cystic lesions in the left temporal lobe and herniation of the cerebral falx (Fig. 1a). Laboratory analysis showed that his leukocyte count $\left(10.94 \times 10^{9} / \mathrm{L}\right)$ was elevated. Creactive protein $(30 \mathrm{mg} / \mathrm{L})$, glycosylated hemoglobin $(6.2 \%)$, total cholesterol $(7.78 \mathrm{mmol} / \mathrm{L})$, triglycerides $(1.93 \mathrm{mmol} / \mathrm{L})$, and low-density lipoprotein cholesterol $(4.93 \mathrm{mmol} / \mathrm{L})$ levels were also higher. Fasting blood glucose, and liver and kidney function tests were normal. Electrocardiography showed T-wave changes. Brain magnetic resonance (MR) imaging (MRI) showed massive cystic lesions in the left temporal lobe and cerebral falx herniation (Fig. 1b-e). Brain MR angiography was normal. He was administered an antibiotic (cefoxitin), a diuretic (mannitol) to reduce intracranial pressure, and supportive treatment. On the fourth day after admission, he underwent partial excision of the cystic occupying lesion, internal decompression, and dural repair. On the sixth day after the operation, head CT (Fig. 1f) showed a midline shift, the cerebral edema was alleviated, and the right limb weakness was improved. Pathological examination (Fig. $1 \mathrm{~g}$ ) of the cystic wall of lesions, as well as cyst-fluid smear examination (Fig. $1 \mathrm{~h}$ ), detected no tumor cells.

Six months later, he was readmitted owing to right limb weakness for one week in February 2018. Brain and nasopharynx MRI showed recurrence of cystic lesions in the left temporal lobe and cerebral hernia (Fig. 2a-f). Left frontotemporal craniotomy, surgical resection of brain metastasis, and repair of the skull base and dura were performed one week after admission. The pathology of the cystic wall indicated brain metastasis from NPC (Fig. 2 g). Postoperative $\mathrm{CT}$ showed that the cyst subsided, midline deviation recovered, and brain edema was reduced (Fig. 2 h). Follow-up chest CT demonstrated multiple metastases in both lungs one-and-a-half years postoperatively.

\section{Discussion and conclusions}

In both evaluations of this patient (initial and recurrence), the cystic lesions did not extend from the skull base. Tumor cells were not found in the first pathological examination. Therefore, the first onset was diagnosed as cystic RE of the capsule wall. He had a history of RE as MRI imaging characteristics at the second onset were consistent with cystic RE; however, NPC metastasis was confirmed based on a combination of MRI imaging and the pathology of the capsule wall.

It is rare for NPC to metastasize to the brain through blood or cerebrospinal fluid circulation. A 

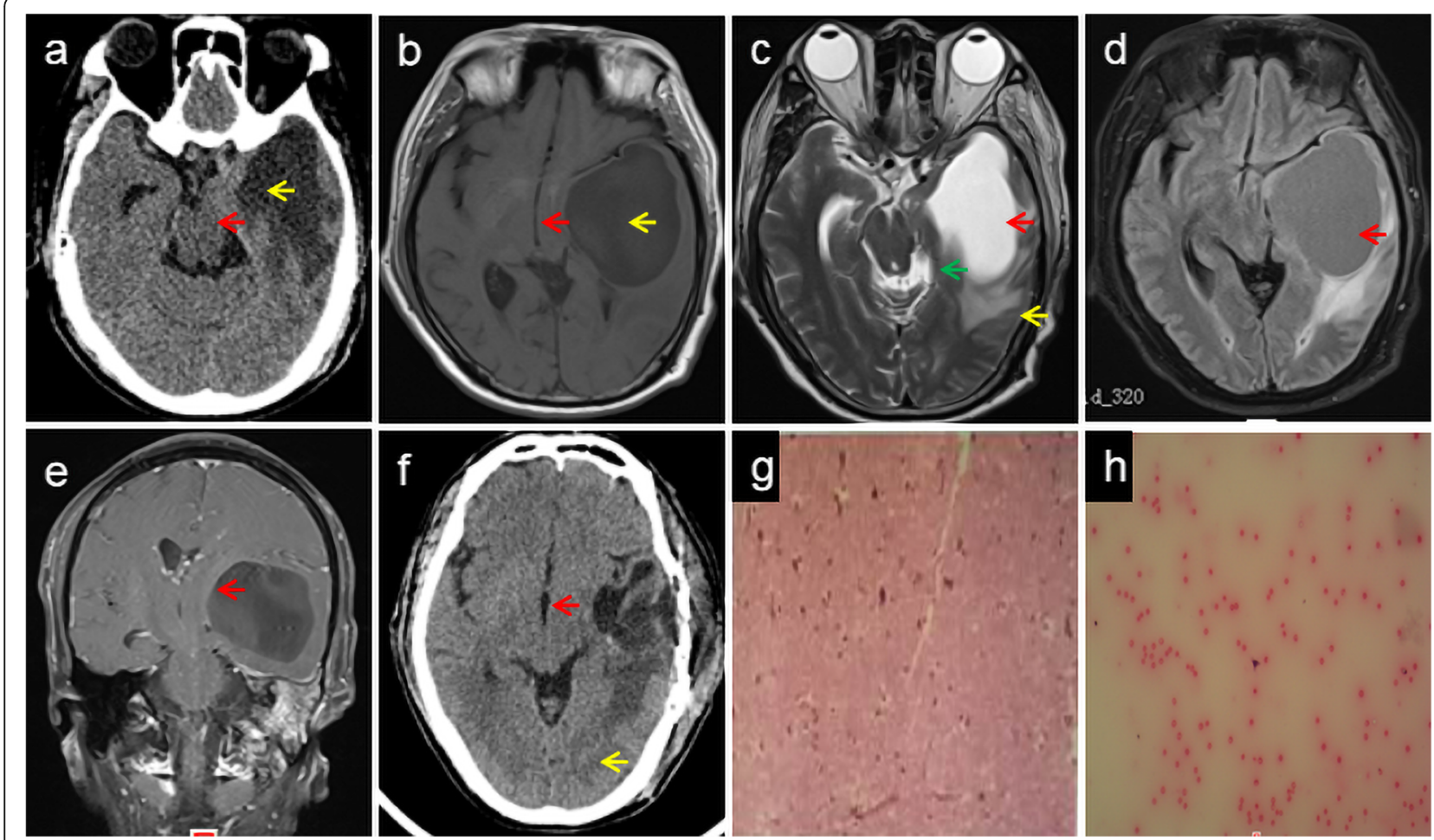

Fig. 1 Neuroimaging and pathological findings in the first hospitalization. CT shows midbrain compression (a, red arrow) and herniation of falx cerebri caused by a massive solid-cystic lesion (a, yellow arrow). Axial T1-WI shows a massive cystic lesion in the left temporal lobe with short T1 signals (b, yellow arrow) and midline shift (b, red arrow). T2-WI shows abnormal long T2 signals (c, red arrow) in the cystic region with cerebral edema around the cyst (c, yellow arrow) and midbrain compression (c, green arrow). Flair imaging shows equal and even signals (d, arrow) in the cystic region. Coronal gadolinium-enhanced magnetic resonance imaging shows the cystic lesion is not enhanced (e, arrow) and did not extend from the skull base. Postoperative CT shows the midline shift (f, red arrow) and cerebral edema (f, yellow arrow) are alleviated. Pathological examination ( $\mathbf{g}$, hematoxylin \& eosin stain, $\times 100)$ of the cystic wall of lesions and cyst-fluid smear examination (h) does not indicate the presence of tumor cells. CT: Computed tomography, Flair: Fluid attenuated inversion recovery, Wl: weighted image

PubMed search revealed only a few well-described relevant cases that did not include spinal metastasis (Table $1[5,8-12]$ ). Perhaps due to the effect of the blood-brain-barrier, the brain is not a typical site for metastasis of NPC [12]. Compared with all cases reported in Table 1, our case had the longest interval time from the diagnosis of NPC to the discovery of the brain metastasis. Some metastases in cases presented in Table 1 showed cystic changes with perifocal edema, although these cystic changes were not as large as in our case, with malignant edema mimicking cystic RE.

At first, the pathophysiology of RE involves brain tissue edema and vascular endothelial injury after radiotherapy, subsequent brain tissue necrosis, gliosis, and granulation tissue formation, followed by encephalomalacia of the lesions and cystic necrosis [13]. The cyst is formed by liquefaction and brain tissue necrosis, and as the fluid and capacity of the cyst increase, it compresses the surrounding brain tissue and causes brain herniation. In our case, cystic RE showed a low signal in T1 weighted MRI images (WI), a high signal in T2 WI, and well-defined round or oval lesions of hyperintensity on T2 WI [14], similar to the characteristics of cystic brain metastasis. Metastasis is a promoter of cystic changes, as tumor cells secrete sufficient amounts of proteins to promote cyst growth, and cancer cells can aggravate vasogenic edema. MRI is a useful and noninvasive method to evaluate RE and its evolution but is usually focused on the temporal lobe. Solid enhanced nodular foci were the earliest MRI abnormalities observed in the patient's RE [14]. Brain metastatic foci can be abnormally enhanced in severe edema with a short T1 WI signal $[5,8]$. It is difficult to distinguish $\mathrm{RE}$ and metastasis by conventional MR sequences, 


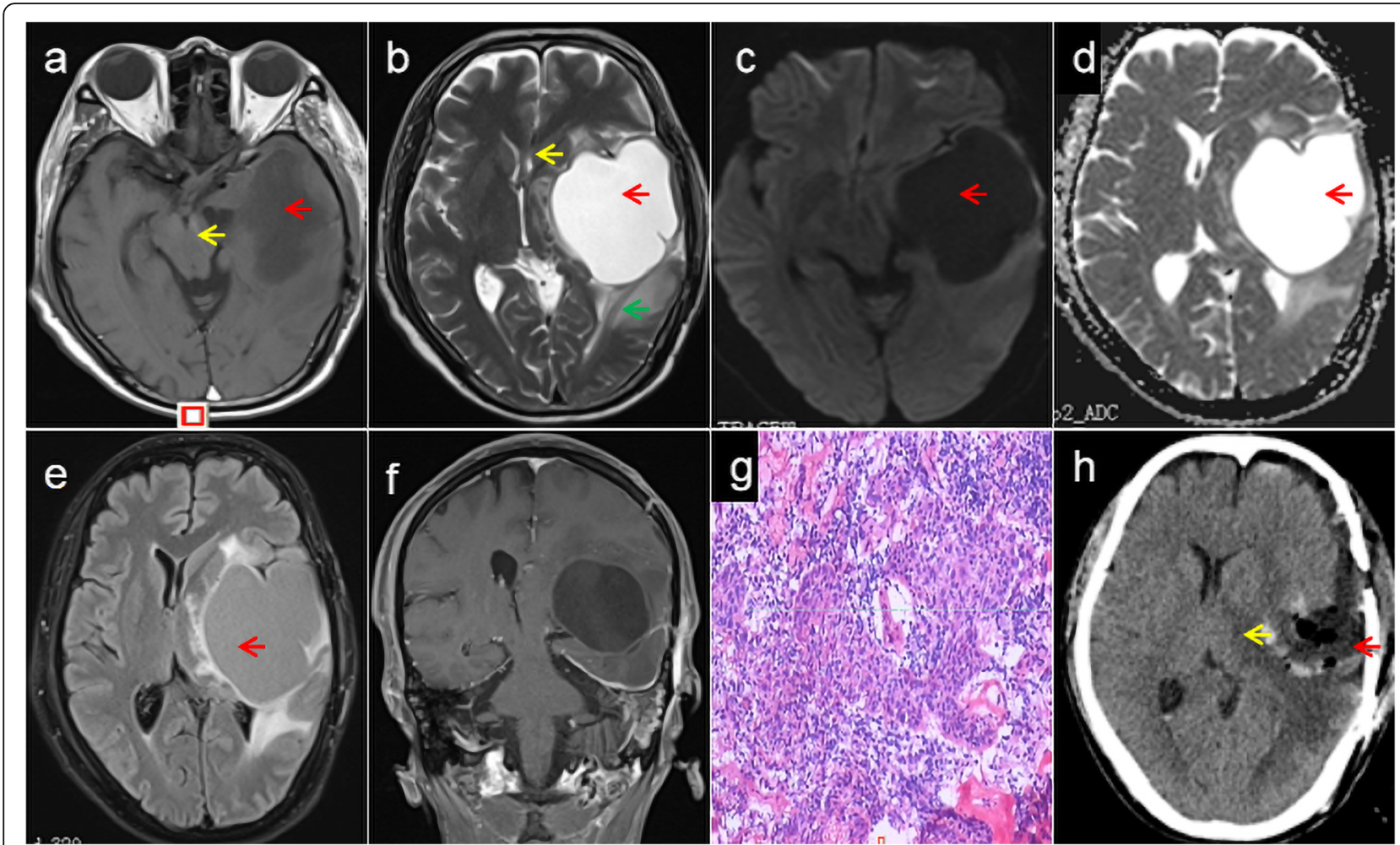

Fig. 2 Neuroimaging and pathological findings in the second hospitalization. Axial T1-WI shows a massive cystic lesion (a, red arrow) in the left temporal lobe with short T1 signals, and midbrain compression (a, yellow arrow). T2-Wl shows long T2 signals (b, red arrow) in the cystic region with cerebral edema around the cyst (green arrow) and midline shift (b, yellow arrow). The signal intensity of the cystic focus region is low on diffusion WI (c, arrow) and high on the apparent diffusion coefficient (d, arrow) map. Flair imaging shows equal and even signals in the cystic region (e) and enhanced magnetic resonance imaging shows no enhancement of the cystic lesion ( $\mathbf{f}$ ). Postoperative pathological examination of the cystic wall indicates infiltrative growth of heteromorphic epithelial cells and inflammatory cell infiltration (g, hematoxylin \& eosin stain, $\times 150)$. Immunohistological examination shows p40 protein (+), p63 protein (+), cytokeratin (+), Ki67 protein (approximately 40\%, +); These findings are consistent with those of the metastasis of differentiated non-keratinizing nasopharyngeal carcinoma. Postoperative computed tomography shows the reduced cyst (red arrow) and midline deviation (h, yellow arrow). Flair: Fluid attenuated inversion recovery, Wl: weighted image

but this can be achieved by perfusion-weighted imaging.

The quantitative detection of serum Epstein-Barr virus (EBV) deoxyribonucleic acid (DNA) may be an indicator for screening and monitoring the recurrence of NPC, and patients with elevated plasma EBV DNA levels are more likely to relapse [15]. However, most of the EBV test results in the cases in Table 1 were negative. The majority of NPCs consist of poorly differentiated squamous cell carcinoma with high degrees of malignancy, and they are highly sensitive to radiotherapy. Individual radiosensitivity is determined by the proportion of lethal chromosomal aberrations in vitro irradiated lymphocytes that might have the potential to predict the morbidity and severity of RE, specifically, patients with a high radiosensitivity had shorter latency of $\mathrm{RE}$ than those with low or intermediate radiosensitivity [16]. Some RE patients can obtain symptomatic relief with high dose corticosteroids in the early stage; if lesions are metastatic, the symptoms may rebound. Operations to reduce intracranial pressure and inflammatory responses can be performed in cystic RE patients with severe symptoms and signs [17]. Our patient was satisfied with the treatments he received and his recovery.

This unique case is notable owing to the extended period before recurrence and brain metastasis from NPC mimicking cystic RE. Hence, multicenter and large-sample clinical studies are needed to confirm the characteristics of brain metastasis from NPC. In conclusion, we determined that when patients present with cystic RE, brain metastasis should be considered as a differential diagnosis. 


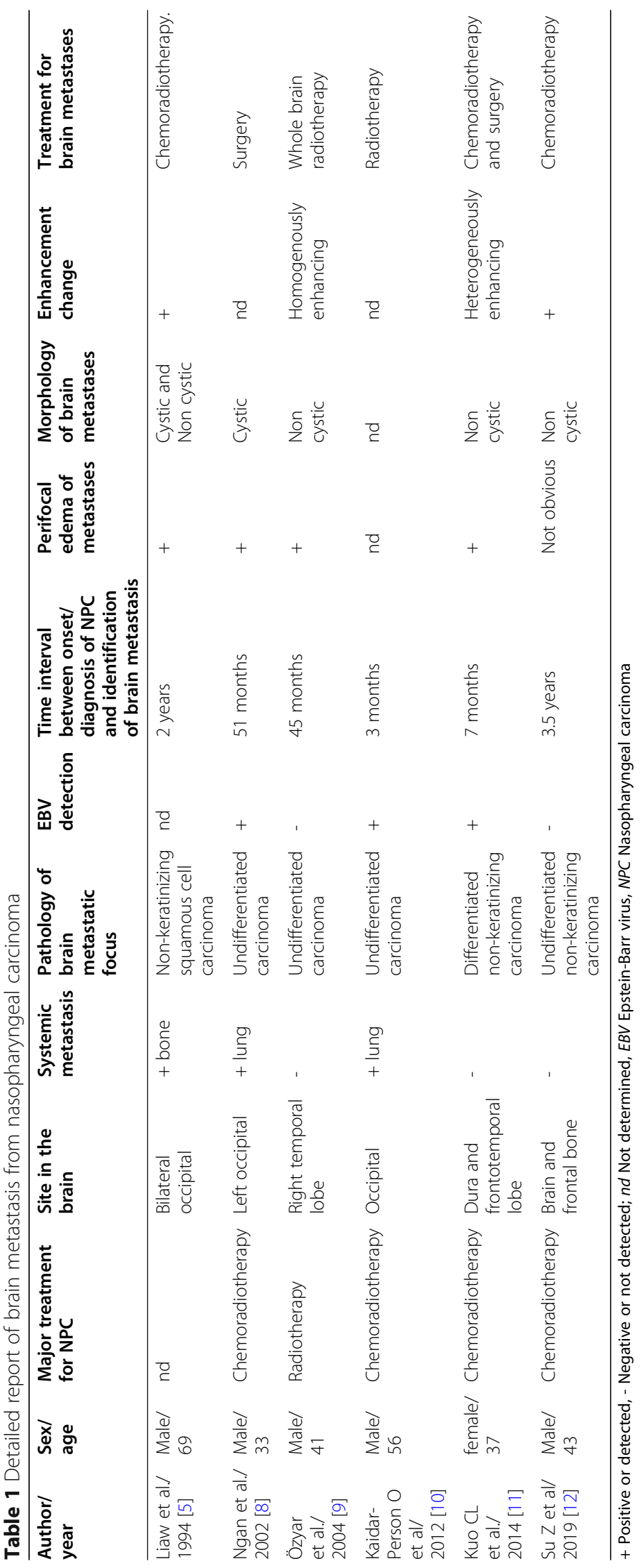




\section{Abbreviations}

NPC: Nasopharyngeal carcinoma; RE: Radiation encephalopathy; CT: Computed tomography; MR: Magnetic resonance; MRI: Magnetic resonance imaging; WI: Weighted image

\section{Acknowledgements}

Not applicable.

\section{Authors' contributions}

Drafted the manuscript: XC. Provided constructive discussion: LR. Analyzed the imaging and provided constructive discussion: GQ. Conceived the study and provided constructive discussion: LC. All authors have read and approved the manuscript.

\section{Funding}

This study was supported by Natural Science Foundation of Liaoning Province of China (No. 2019-MS-200).

\section{Availability of data and materials}

Data sharing not applicable to this article as no datasets were generated or analyzed during the current study.

\section{Ethics approval and consent to participate}

The study design was approved by the ethics review board of the 3rd Affiliated Hospital of Shenzhen University (NO. 2020-SZLH-LW-010). Informed consent was obtained from the patient.

\section{Consent for publication}

The patient quickly deteriorated into a coma after the second admission. His postoperative cognition was such that he could not normally communicate with others. Therefore, he was not able to provide informed consent for publication. We obtained written consent for publication from the patient legal guardian

\section{Competing interests}

No potential conflict of interest relevant to this article was reported.

\section{Author details}

'Department of Neurology, Peking University Shenzhen Hospital, 518000 Shenzhen, China. ${ }^{2}$ Department of Neurology, Shenzhen University First Affiliated Hospital, 3002 Sungang West Road, Futian District 518000 Shenzhen, China. ${ }^{3}$ Department of Neurology, Shenzhen Second People's Hospital, 518000 Shenzhen, China. ${ }^{4}$ Department of Neurology, The 3rd Affiliated Hospital of Shenzhen University, 518000 Shenzhen, China.

Received: 1 August 2020 Accepted: 2 February 2021

Published online: 08 February 2021

\section{References}

1. Zhou GQ, Yu XL, Chen M, Guo R, Lei Y, Sun Y, et al. Radiation-induced temporal lobe injury for nasopharyngeal carcinoma: A comparison of intensity- modulated radiotherapy and conventional two-dimensional radiotherapy. PLoS One. 2013;8(7):e67488. https://doi.org/10.1371/journal. pone.0067488.

2. Chen X, Li J, Lin S, Hu C. Expert consensus on the diagnosis of recurrent or metastatic nasopharyngeal carcinoma. Chin J Radiat Oncol. 2018;27(1):7-15. [Chinese].

3. Zeng L, Tian YM, Huang Y, Sun XM, Wang FH, Deng XW, et al. Retrospective analysis of 234 nasopharyngeal carcinoma patients with distant metastasis at initial diagnosis: therapeutic approaches and prognostic factors. PLoS One. 2014;9(9):e108070. https://doi.org/10.1371/journal.pone.0108070.

4. Elloumi F, Ben Amor M, Ghorbel L, Mnif H, Boudawara T, Ghorbel AM, et al. Clinical aspects of brain metastases from nasopharyngeal carcinoma. Cancer Radiother. 2013;17(8):768-70. https://doi.org/10.1016/j.canrad.2013.09.004.

5. Liaw CC, Ho YS, Koon-Kwan NG, Chen TL, Tzann WC. Nasopharyngeal carcinoma with brain metastasis: a case report. J Neurooncol. 1994;22(3): 227-30. https://doi.org/10.1007/BF01052923.

6. Anne WML, Wai TN, Jimmy YWC, June C, Antti M, William MM, et al. Management of locally recurrent nasopharyngeal carcinoma. Cancer Treat Rev. 2019;79:101890. https://doi.org/10.1016/j.ctrv.2019.101890.
7. Huang CJ, Leung SW, Lian SL, Wang CJ, Fang FM, Ho YH. Patterns of distant metastases in nasopharyngeal carcinoma. Kaohsiung J Med Sci. 1996;12(4): 229-34.

8. Ngan RK, Yiu HH, Cheng HK, Chan JK, Sin VC, Lau WH. Central nervous system metastasis from nasopharyngeal carcinoma: a report of two patients and a review of the literature. Cancer. 2002;94(2):398-405. https://doi.org/1 $0.1002 /$ cncr.10179.

9. Özyar E, Yazici G, Tezel G, Cila A, Özcan OE. Undifferentiated nasopharyngeal carcinoma with isolated central nervous system metastasis. Arch Oncol. 2004;12(2):121-3.

10. Kaidar-Person O, Kuten J, Atrash F, Billan S, Kuten A. Brain metastasis of nasopharyngeal carcinoma: A case report and literature review. Case Rep Med. 2012;2012:405917. https://doi.org/10.1155/2012/405917.

11. Kuo CL, Ho DMT, Ho CY. Dural metastasis of nasopharyngeal carcinoma:rare, but worth considering. Singapore Med J. 2014;55(5):e82-4. https://doi.org/1 $0.11622 /$ smedj.2013214.

12. Su Z, Cao X, Zou G. Brain and frontal-bone metastasis from nasopharyngeal carcinoma: Case report and literature review. Head Neck. 2019; 41(9):E153-8 https://doi.org/10.1002/hed.25859.

13. Hong J, Li J, Tu Q, Wang X, Zhang Z. Multivariate analysis of radiation induced encephalopathy in nasopharyngeal carcinoma. Chin J Radiol Med Prot. 2004:24(2):140-1. [Chinese].

14. Zhou X, Liao X, Ren X, Xiang K, Hu Q, Zhang M, et al. Dynamic MRI followup of radiation encephalopathy in the temporal lobe following nasopharyngeal carcinoma radiotherapy. Oncol Lett. 2017;14(1):715-24. https://doi.org/10.3892/ol.2017.6199.

15. Lin JC, Wang WY, Chen KY, Wei YH, Liang WM, Jan JS, et al. Quantification of plasma Epstein-Barr virus dnain patients with advanced nasopharyngeal carcinoma. N Engl J Med. 2004;350(24):2461-70. https://doi.org/10.1056/ NEJMoa032260

16. Tang $Y$, Zhang Y, Guo L, Peng Y, Luo Q, Xing Y. Relationship between individual radiosensitivity and radiation encephalopathy of nasopharyngeal carcinoma after radiotherapy. Strahlenther Onkol. 2008;184:510-4. https:// doi.org/10.1007/s00066-008-1898-Z.

17. Fang W, Gu B, Jing X, Xiao S, Fan S, Liao W, et al. Late-onset cystic brain necrosis after radiotherapy for nasopharyngeal carcinoma. Jpn J Clin Oncol. 2017:47:499-504. https://doi.org/10.1093/jjco/hyx028.

\section{Publisher's Note}

Springer Nature remains neutral with regard to jurisdictional claims in published maps and institutional affiliations.

Ready to submit your research? Choose BMC and benefit from:

- fast, convenient online submission

- thorough peer review by experienced researchers in your field

- rapid publication on acceptance

- support for research data, including large and complex data types

- gold Open Access which fosters wider collaboration and increased citations

- maximum visibility for your research: over $100 \mathrm{M}$ website views per year

At $\mathrm{BMC}$, research is always in progress.

Learn more biomedcentral.com/submissions 